\title{
Risk factors associated with low birth weight of neonates among pregnant women attending a referral hospital in northern Tanzania
}

\author{
J.E. SIZA \\ National Institute for Medical Research, Mwanza Research Centre, \\ P.O. Box 1462, Mwanza, Tanzania \\ Email: sjulius2002@yahoo.co.uk
}

\begin{abstract}
According to the World Health Organization low birth weight (LBW) babies are those born with less than $2500 \mathrm{~g}$. A descriptive retrospective cross - sectional study using existing data from a one-year (2001) block of birth registers of 3464 pregnant women was done at Kilimanjaro Christian Medical Centre in Moshi, Tanzania. The objective was to determine factors associated with LBW and their contribution to the problem. Out of 648 pregnant women who were tested for HIV infection 59 (9.1\%) were positive for the infection. Twelve $(20.3 \%)$ of HIV positive women gave birth to LBW neonates. HIV positive women were twice more likely to give birth to LBW infants than HIV negative ones $\left(\chi^{2}=6.7 ; P<0.01 ;\right.$ OR $=2.4 ; 1.1,5.1)$. Mothers without formal education were 4 times more likely to give birth to LBW neonates than those who had attained higher education $(\mathrm{OR}=3.6 ; 2.2,5.9)$. There was a linear decrease in low birth weights of newborns as fraternal educational level increased $\left(\chi^{2}\right.$ for linear trend $\left.=42.7 ; P<0.01\right)$. There was no statistically significant difference among parents' occupations regarding LBW of their newborns. Unmarried mothers were more likely to give birth to LBW neonates as compared to their married counterparts $(\mathrm{OR}=1.65 ; 1.2,2.2)$ and the difference was statistically significant $\left(\chi^{2}=13.0, P<0.01\right)$. Hypertension, pre-eclampsia and eclampsia disease complex had the highest prevalence $(46.67 \%)$ and population attributable fraction of low birth weight $(\mathrm{PAF}=25.2 \% ; \mathrm{CI}=22.0-27.6)$. Bleeding and schistosomiasis had the same prevalence $(33.33 \%)$ of LBW babies. Other complications and diseases which contributed to high prevalence of LBW included anaemia (25\%), thromboembolic diseases (20\%), tuberculosis (17\%) and malaria (14.8\%). Prevalence of LBW was high in women with premature rupture of membrane $(38 \%)$, placenta previa $(17 \%)$ and abruption of placenta $(15.5 \%)$. LBW was strongly associated with gestational age below 37 weeks $(\mathrm{OR}=2 ; \mathrm{CI}=1.5,2.8)$ contributing to $42 \%$ of LBW deliveries in the study population $(\mathrm{PAF}=42.4 \%: 25,55)$. Pregnant women with malnutrition $(\mathrm{BMI}<18)$ gave the highest proportions $17 \%$ of LBW children followed by underweight (BMI; 18-22) who gave 15.5\% of LBW neonates. There was a statistical significant difference between the proportions of LBW infants from mothers who did not receive antenatal care $(28.6 \%)$ and those who attended for the services $(13.8 \%)\left(\chi^{2}=8.8 ; P=0.01\right)$. There is need of increasing promotion of reproductive health services in relation to safe motherhood at community level in order to reduce risk factors of LBW.
\end{abstract}

Key words: Low birth weight, pregnancy, risk factors, hospital, Tanzania

\section{Introduction}

World-wide, about $16 \%$ of live births, or some 20 million infants per year, are born with less than $2500 \mathrm{~g}$ of weight and $90 \%$ of them are born in developing countries (McCormick et al. 1990). The prevalence of low-birth weight (LBW) varies between and within geographical regions (WHO, 1980). The Middle South Asia leads with a prevalence of $31.1 \%$ while Asia as a whole has a prevalence of $19.7 \%$. The prevalence of LBW in North America and Europe is 6.8\% and $6.5 \%$ respectively (Villar \& Belizan, 1982). In Latin America the percentage of LBW infants is $10.1 \%$ whereas in Africa, it is estimated at $14 \%$ (WHO 1980). A recent study in Tanzania reported a proportion of LBW neonates among term babies ranging between $56 \%$ and $62 \%$ (Klingenberg et. al., 2003).

Birth weight is a powerful predictor of infant growth and survival. Infants born with low birth weights begin life immediately disadvantaged and face extremely poor survival rates. In most developing countries it was approximated that every ten seconds an infant dies from a disease or infection that can be attributed to low birth weight (Villar \& Belizan, 1982). Many of those infants who survive suffer cognitive and neurological impairment, increased risk of high blood pressure, obstructive lung disease, cholesterol, renal damage, acute diarrhoea, impaired immune function and poor cognitive development (Fonseca et al 1990; McLachlan, 1999; Podja \& Kelley, 2000; Jurjus, 1995). Generally the risk of neonatal mortality for LBW infants is 25 to 30 times greater than for infants with birth weight exceeding $2500 \mathrm{~g}$, and it increases sharply as birth weight decreases (Podja \& Kelley, 2000). The increase in survival rates of LBW infants leads to increasing health care costs due to extensive hospital stays. It is estimated that extremely LBW babies are up to six times as costly as normal weight babies (Chang, 2003; Klingenberg et al; 2003).

Low birth weight can be caused either by premature delivery (short gestation) or by foetal growth retardation. Known factors for pre-term delivery and 
foetal growth retardation which are associated with LBW include low maternal food intake, hard physical work during pregnancy, and illness, especially infections (Klingenberg et al, 2003; Renqvist et al., 1994). Several studies suggest that cigarette smoking, genetic and environmental factors can cause LBW (Bang et al., 1999), short maternal stature, very young age, high parity, close birth spacing, high C8 cell counts in HIV infections are all associated factors (UNAIDS, 1999; Verma \& Das, 2003) A recent study in Tanzania showed that the risk of giving birth to a low birth weight baby increased with severity of HIV infection in pregnant women (Dreyfuss et al., 2001). Many of the mentioned factors are prevalent among disadvantaged communities.

One of the goals of the 1990 World Summit for Children was to reduce the prevalence of low birth weight to less than $10 \%$ by the year 2000 (Boerma et al.,1996; Podja \& Kelly, 2000). However, this remains a formidable challenge to-date. It is therefore encouraging that the international public health community has begun to increase its attention toward these four million infants who die each year and the many more that survive with a diminished quality of life. Low birth weight is a reasonable well-defined problem caused by factors that are potentially modifiable and the costs of preventing them are well within reach, even in poor countries like Tanzania. It is therefore imperative to identify risk factors for LBW in various communities in the country in order to come up with feasible intervention strategies to minimise the problem. This study was carried out to determine factors associated with low birth weight and compare their effects between pre-term and full term babies and their respective attributable fraction at the Kilimanjaro Christian Medical Centre in northern Tanzania.

\section{Materials and Methods}

\section{Source of data}

The study was done at Kilimanjaro Christian Medical Centre (KCMC) Referral Hospital in Moshi in northern Tanzania. The hospital has a large catchment area with about 10 million inhabitants, mainly from the northern zone of Tanzania which include Tanga, Kilimanjaro, Arusha, Manyara and Singida Regions.
About 4000 deliveries take place at KCMC annually. A block of 3464 birth registers for pregnant women who gave birth at the hospital in 2001 was reviewed for the factors associated with LBW.

Factors selected from the birth registers were those associated with low birth weights according to studies done elsewhere (Kramer, 1987; UNICEF \& WHO, 2004; Tema, 2006). The factors included maternal educational level, marital status, tribe (ethnic group), mother's body weight and height before pregnant, presence of serious disease(s) before delivery, antenatal care, complications during delivery, smoking and alcoholic intake before childbirth.

\section{Data analysis}

Data cleaning and analysis was done using Stata version 8.0 (Stata Corporation, College Park, Texas) and Epi info version 6.04 (Centers for Disease Control and Prevention and the World Health Organization, Geneva, Switzerland).

\section{Results}

A total of 3464 pregnant women delivered at the KCMC referral hospital in 2001. Of these, 469 (13.6\%) gave birth to low birth weight neonates. Mean weight for registered mothers was $61.28 \pm 11.39 \mathrm{~kg}$ and the mean height was $158.89 \pm 6.75 \mathrm{~cm}$. Most (76\%) of the pregnant women were in the 20-35 years age group (mean age $=26.61 \pm 6.09$ years) (Table 1 ). The proportion of low birth weight deriveries decreased as maternal formal education level increased $\left(\chi^{2}\right.$ for trend $=35.22, \mathrm{df}=3 ; P<0.01)$.

Out of 2075 pregnant women from rural areas $322(15.51 \%)$ gave birth to low birth weight infants. Low birth weight deliveries from urban areas were 153 $(11.29 \%)$. Unmarried women were almost twice more likely to give birth to LBW neonates than the maried ones $(\mathrm{OR}=1.65 ;(95 \% \mathrm{CI}=1.25-2.17))$ contributing to about $5 \%$ of all low birth weights $(\mathrm{PAF}=5.4 \%(\mathrm{CI}=$ 2.8- 7.4). The highest proportion (32.26\%) of low birth weights was observed in the Masai and the Chaga (11.95\%) ethnic groups.

A statistically significant difference in low birth weight as a result of variations in the types of maternal occupations $\left(\chi^{2}=25 ; \mathrm{df} ;=5 ; P<0.01\right)$ was observed. Women who were peasants had the highest proportion $(17.50 \%)$ of LBW neonates of all the ma- 
Table 1: Distribution of infant birth weight status by martenal age and education

\begin{tabular}{|c|c|c|c|c|}
\hline Variable & $\begin{array}{l}\text { LBW } \\
\text { No (Row\%) }\end{array}$ & $\begin{array}{l}\text { NBW } \\
\text { No (Row \%) }\end{array}$ & $\begin{array}{l}\text { Prev.of r/factor } \\
\text { No (Col. \%) }\end{array}$ & $\begin{array}{l}\mathrm{OR}(\mathrm{CI}), \operatorname{PAF}(\mathrm{Cl}) \chi^{2} \text {, and } \mathrm{P} \text { - } \\
\text { value }\end{array}$ \\
\hline \multicolumn{5}{|c|}{ Mother's age group (years) } \\
\hline $36-50$ & $52(12.84)$ & $353(87.16)$ & 405 (11.78) & $\mathrm{OR}=1.0$ \\
\hline \multirow[t]{2}{*}{$20-35$} & $381(14.57)$ & $2233(85.43)$ & $2614(76.05)$ & $\begin{array}{l}\mathrm{OR}=1.16(0.85,1.58) \\
\mathrm{PAF}=10.5 \%(-13.6,28.8)\end{array}$ \\
\hline & $50(11.96)$ & 368 (88.04) & $418(12.16)$ & OR=1.08 $(0.72,1.64)$ \\
\hline $13-19$ & & & & $\mathrm{PAF}=3.5 \%(-7.3,18.0)$ \\
\hline Total & $483(14.05)$ & $2,954(85.95)$ & $3,437(100)$ & $\begin{aligned} \chi^{2} & =2.6, d f=2 \\
p & =0.272\end{aligned}$ \\
\hline \multicolumn{5}{|c|}{ Mother's education } \\
\hline Higher & $78(09.45)$ & $747 \quad(90.55)$ & $825(24.09)$ & $\mathrm{OR}=1.0$ \\
\hline Secondary & $13(09.09)$ & $130(90.91)$ & $143(4.18)$ & $\begin{array}{l}\text { OR=0.96 }(0.52,1.77) \\
\text { PPF } 0.5 \%(6.4,-9.8)\end{array}$ \\
\hline Primary & $363(15.39)$ & $1,995(84.61)$ & $2,358(68.85)$ & $\begin{array}{l}O R=1.74 \quad(1.35,2.26) \\
P A F=31.8(18.6,42.2)\end{array}$ \\
\hline None & $27 \quad(27.27)$ & 72 (72.73) & 99 (2.89) & $\begin{array}{l}\mathrm{OR}=3.59 \quad(2.18, \quad 5.92) \\
\mathrm{PPF}=16.8 \%(12.6,19.6)\end{array}$ \\
\hline Total & $481 \quad(14.04)$ & $2,944(85.96)$ & $3,425(100.0)$ & $\chi^{2}=35.22, \quad d f=3 ; p<0.01$ \\
\hline
\end{tabular}

Key : OR= Odds ratio; $\mathrm{PAF}=$ Population attributable risk; $\mathrm{Cl}$ : $95 \%$ Confidence interval in brackets;

$P$-value if less than 0.05 then there was a statistically significant difference between or among variables

ternal occupations recorded with twice the likelihood of delivering low birth weight babies than housewives $(\mathrm{OR}=1.99 ; \mathrm{CI}=1.36-2.91)$ and $\mathrm{PAF}=39 \%(\mathrm{CI}=$ 19.1-52.9).

The highest prevalence (17.14\%) of low birth weight infants was observed in mothers who were malnourished (Body Mass Index (BMI) $<18$ ). Generally the proportions decreased as the anthropometric measurement increased and the interclass differences were statistically significant $\left(\chi^{2}\right.$ trend $\left.=25 ; P<0.01\right)$ (Table 2).

Table 2: Distribution of infant birth weight status by maternalanthropometricindices and antenatal care

\begin{tabular}{|c|c|c|c|c|}
\hline Variable & $\begin{array}{c}\text { LBW } \\
\text { No (Row\%) }\end{array}$ & $\begin{array}{c}\text { NBW } \\
\text { No (Row \%) }\end{array}$ & $\begin{array}{l}\text { Prev.of r/factor } \\
\text { No (Col. \%) }\end{array}$ & $\begin{array}{l}\text { OR(CI), PAF(CI) } \chi^{2} \text { and } \\
\text { P-value }\end{array}$ \\
\hline \multicolumn{5}{|c|}{ Mother's body mass index } \\
\hline $\begin{array}{l}\text { Normal } \\
22-25\end{array}$ & $110(12.68)$ & $757 \quad(87.32)$ & $867(27.31)$ & $\mathrm{OR}=1.0$ \\
\hline $\begin{array}{l}\text { Malnutrition } \\
<18\end{array}$ & $12(17.14)$ & $58 \quad(82.86)$ & $70(2.20)$ & $\begin{array}{l}\text { OR=1.42 }(0.74,2.74) \\
\text { PAF }=2.6 \%(-2.7,5.6)\end{array}$ \\
\hline $\begin{array}{l}\text { Underweight } \\
18-22\end{array}$ & $209(15.55)$ & $1,135 \quad(84.45)$ & $1,344(42.33)$ & $\begin{array}{l}\mathrm{OR}=1.27(.99,-1.62) \\
P A F=12.1 \%(-0.7,22.4)\end{array}$ \\
\hline Overweight & 59 (08.94) & $601 \quad(91.06)$ & $660(20.78)$ & $\begin{array}{l}O R=0.68(0.48,0.94) \\
P P F=10.3 \%(16.7,1.7)\end{array}$ \\
\hline $\begin{array}{l}\text { Obese } \\
25-30\end{array}$ & $21 \quad(10.00)$ & $189 \quad(90.00)$ & $210(6.61)$ & $\begin{array}{l}\text { OR=0.76 }(0.47,1.25) \\
P P F=3.4 \%(7.9,-3.6)\end{array}$ \\
\hline $\begin{array}{l}\text { Great obese } \\
30-35\end{array}$ & $1(4.17)$ & $23 \quad(95.83)$ & $24(0.76)$ & $\begin{array}{l}\mathrm{OR}=0.3(0.04,2.24) \\
\mathrm{PPF}=0.6 \%(0.9,-1.1)\end{array}$ \\
\hline Total & $412(12.98)$ & $2,763 \quad(87.02)$ & $3,175(100.00)$ & $\chi 2=25 ; d f=4 ; \quad P<0.01$ \\
\hline \multicolumn{5}{|c|}{ Mother's antenatal care } \\
\hline Attended & 465 (13.78) & 2,908 (86.22) & $3,373(98.57)$ & $\mathrm{OR}=1.0$ \\
\hline Not attended & $14 \quad(28.57)$ & $35 \quad(71.43)$ & $49(1.43)$ & $\begin{aligned} \mathrm{OR} & =2.50(1.34,4.69) \\
\mathrm{PAF} & =1.5 \%(0.7,2.0)\end{aligned}$ \\
\hline Total & $479(14.00)$ & $2,943(86.00)$ & $3,422(100.0)$ & $\chi 2=8.77 ; p<0.01$ \\
\hline
\end{tabular}


Antenatal care had a strong influence on birth weight. Pregnant women who did not attend antenatal care service had about a third (28.57\%) of their neonates in the LBW group as compared with $13.78 \%$ of those who attended. Frequency of intake of alcoholic beverages seemed to influence birth weight only in pregnant women who took the drinks on regular basis. Both maternal and partenal religious denominations as well as their smoking habits did not show any influence in birth weights in the study subjects.
Variations in fraternal occupation, formal education and ethinicity had similar influences on birth weights as they were in mothers.

Table 3 shows the association between maternal complications, diseases, and accidents during pregnancy with low birth weights in a descending order of prevalence. Hypertension, pre-eclampsia and eclampsia disease complex had the highest prevalence (46.67\%) among women who had babies with low birth weight.

Table 3: Distribution of infant birth weights according to Maternal history of complications, diseases and accidents

\begin{tabular}{|c|c|c|c|c|}
\hline $\begin{array}{l}\text { Mother's health } \\
\text { during pregnancy }\end{array}$ & $\begin{array}{c}\text { LBW } \\
\text { No (Row \%) }\end{array}$ & $\begin{array}{c}\text { NBW } \\
\text { No (Row \%) }\end{array}$ & $\begin{array}{l}\text { Prevalence of } \\
\text { risk factor } \\
\text { No (Col. \%) }\end{array}$ & $\mathrm{OR}(\mathrm{Cl}), \mathrm{PAF}(\mathrm{Cl})$ \\
\hline No complication & $104(9.20)$ & $1025(90.80)$ & 1,130 (32.99) & $\mathrm{OR}=1.0$ \\
\hline Any complication & $375(16.34)$ & $1921(83.66)$ & $2295(67.0)$ & $\begin{array}{l}\mathrm{OR}=1.92(1.53,2.42) \\
\mathrm{PAF}=34.1 \%(24.1,42.3)\end{array}$ \\
\hline $\begin{array}{l}\text { Hypertension, } \\
\text { preeclampsia, } \\
\text { Eclampsia }\end{array}$ & $56(46.67)$ & $114(54.33)$ & $120(3.50)$ & $\begin{array}{l}\mathrm{OR}=4.84(3.32,7.07) \\
\mathrm{PAF}=25.2 \%(22,27.6)\end{array}$ \\
\hline Bleeding & $23 \quad(33.33)$ & $46(66.67)$ & $69 \quad(2.01)$ & $\begin{array}{l}\mathrm{OR}=4.93(2.87,8,45) \\
\mathrm{PAF}=13.1 \%(10.8,14.7)\end{array}$ \\
\hline Schistomiasis & $3(33.33)$ & $9 \quad(66.67)$ & $12(0.35)$ & $\begin{array}{l}\mathrm{OR}=3.29(0.88,12.32) \\
\mathrm{PAF}=1.8 \%(0.0,2.4)\end{array}$ \\
\hline Anaemia & $6 \quad(25.00)$ & $18 \quad(75.00)$ & $24 \quad(0.70)$ & $\begin{array}{l}\mathrm{OR}=3.3(1.28,8.46) \\
\mathrm{PAF}=3.4 \%(1.3,4.5)\end{array}$ \\
\hline $\begin{array}{l}\text { Thrombo-embolic } \\
\text { diseases }\end{array}$ & $1(20.00)$ & $4 \quad(80.00)$ & $5 \quad(0.14)$ & $\begin{array}{l}\mathrm{OR}=2.46(0.27,22.25) \\
\mathrm{PAF}=0.5 \%(-1.6,0.9)\end{array}$ \\
\hline Tuberculosis & $18(16.98)$ & $88 \quad(83.02)$ & 106 (3.09) & $\begin{array}{l}\mathrm{OR}=2.02(1.17,) 3.48 \\
\mathrm{PAF}=6.8 \%(2.1,9.7)\end{array}$ \\
\hline Malaria & $107(14.84)$ & $614 \quad(85.16)$ & 721 (21.05) & $\begin{array}{l}\text { OR1.71 }(1.28,2.28) \\
P A F=19.1 \%(10.0,26.2)\end{array}$ \\
\hline Hyperemesis & $12(14.11)$ & $73 \quad(85.89)$ & 85 (2.48) & $\begin{array}{l}\text { OR1.62 }(0.85,3.08) \\
P A F=3.6 \%(-1.4,6.5)\end{array}$ \\
\hline $\begin{array}{l}\text { Infections } \\
\text { (specified }\end{array}$ & $146(13.45)$ & $939 \quad(86.55)$ & $1,085 \quad(31.68)$ & $\begin{array}{l}\mathrm{OR}=1.53(1.17,2.0) \\
\mathrm{PAF}=18.4 \%(7.7,26.7)\end{array}$ \\
\hline Gestational diabetes, & $02(11.11)$ & $16 \quad(88.89)$ & $18 \quad(0.52)$ & $\begin{array}{l}O R=1.23(0.28,5.43) \\
P A F=0.3 \%(-4.0,1.5)\end{array}$ \\
\hline Total & $479(13.98)$ & $2946(86.02)$ & $3425(100.00)$ & \\
\hline
\end{tabular}


Table 4: Gestation age and infant sex distributions of infants birth weight status

\begin{tabular}{|c|c|c|c|c|c|c|c|}
\hline & \multicolumn{2}{|c|}{ LBW } & \multicolumn{2}{|c|}{ NBW } & \multicolumn{2}{|c|}{ Total } & \multirow{2}{*}{$\begin{array}{l}\text { OR(CI), PAF(CI) } \chi^{2}, \\
\text { and } p \text {-value }\end{array}$} \\
\hline & No & (\%) & No & $(\%)$ & No & $(\%)$ & \\
\hline \multicolumn{8}{|c|}{ Gestation age (weeks) } \\
\hline $37-43$ & 42 & (09.37) & 489 & (90.63) & 538 & (92.58) & $O R=1.0$ \\
\hline $27-36$ & 418 & $(67.87)$ & 2399 & $(32.13)$ & 2844 & (7.42) & $\begin{array}{l}\mathrm{OR}=2.03(1.46,2.83) ; \\
\mathrm{PAF}=42.4 \%(25.3,55.1)\end{array}$ \\
\hline Total & 460 & (13.71) & 2888 & $(86.29)$ & 3,382 & $(100.0)$ & $\chi^{2}=18.09 ; P<0.01$ \\
\hline \multicolumn{8}{|c|}{ Sex of infants } \\
\hline Males & 210 & $(44.78)$ & 1532 & (52.34) & 1742 & $(51.29)$ & $\mathrm{OR}=1.0$ \\
\hline Females & 259 & $(55.22)$ & 1395 & $(47.66)$ & 1654 & (48.71) & $\begin{array}{l}\mathrm{OR}=1.35(1.11,1.65) \\
\mathrm{PAF}=12.7 \%(4.9,19.3)\end{array}$ \\
\hline Total & 469 & 100.00) & 2927 & (100.0) & 3396 & $(100.0)$ & $\chi^{2}=9.26 P<0.01$ \\
\hline
\end{tabular}

The disease complex also had the highest contribution to low birth weight of them all ( $\mathrm{PAF}=25.2 \%$; $\mathrm{CI}=$ 22.0-27.6). Among the 648 pregnant women who were tested for HIV, 68 (10.49\%) gave birth to low birth weight. Among the HIV positive mothers, 12 (20.34) gave lowbirth weight neonates.Althogh no stage of infection of HIV was indicated in the hospital records HIV positive pregnant women were two times more likely to give birth to LBW neonates as compared with the HIV negative ones $(\mathrm{OR}=2.43 ;(\mathrm{CI}=1.15-5.07)$; $\mathrm{PAF}=9.4 \%(3.2-12.9)$ and the difference between the two grooups was statistcally significant $\left(\chi^{2}=6.69 ; P<\right.$ $0.01)$. Women with common maternal complications during delivery namely abruption placenta and placenta previa had the highest proportions of low birth weight babies of 50 and $45 \%$, respectively

The gestation age and infant sex distributions by birth weight categories are summarised in Table 4 . Out of 460 low birth weight babies born, 418 (90.87\%) were born pre-term, at gestation age below 37 weeks. Premature deliveries were two times likely to result into low birth weight $(\mathrm{OR}=2.03 \mathrm{CI}=1.46-2.83)$ and contributed about $42.4 \%$ of the problem $(42.4 \%$; $\mathrm{CI}=$ $25.3-55.1)$. The prevalence of low birth weight was higher $(15.66 \%)$ in females than in males $(12.06 \%)$ and the difference was statistically significant $\left(\chi^{2}=\right.$ 9.26, $P<0.01)$.

\section{Discussion}

Findings from this study show that most of the women who gave birth at the Kilimanjaro Christian Medical Centre were in the 20 to 35 years age group. Although this is the recommended reproductive age group, was responsible for the highest proportion of low birth weight infants. The percentage of lowbirth weight observed in this study $(13.6 \%)$ was similar to that reported in the Eastern Africa countries (UNICEF, 2004). Malnourished mothers and underweight gave rise to the higher proportions of low birth weight babies. The likelihood of these women to deliver low birth weight babies concured with findings from a study done among pregnant women in East Java (Kusin et al., 1994; Mathule et al., 2005). In this study, maternal occupation could not lead to a sound deduction as they were not scientifically classified and unclear. For instance a housewife could at the same time be a peasant, businesswoman or unemployed. Many Combinations were probable in fraternal occupations thus the factor could not reflect any socio economic effect on birth weight.

While more than half of all mothers took alcohol only $3 \%$ did this daily and the strengths of the alcohol were not mentioned. This could be the reason why drinking did not feature as one of the factors for low birth weight in the study area. Similarly, although smoking is one of the most frequently mentioned factors for low birth weight (Bull et. al., 2003) it could not be associated with either pre term or small for gestation age weights in this study. 
The higher risk of giving birth to low birth weight babies in women who lived single as compared with married ones reflects the importance of socioeconomic support on maternal health and birth outcomes. Mother's antenatal care was associated with infant birth weight. However most of mothers start attending reproductive and child health $(\mathrm{RCH})$ clinics in their sixth to seventh months of gestation such that most pregnant women who deliver prematurely (gestation age less than 37 weeks) are normally not included in RCH clinic attenders (Ahmed \& Behrman, 1990).

Although no seasons were reported along with birth records the highest proportion of low birth weight infants observed among mothers who were peasants could be attributed to the strenuous work they were subjected to in the field. Farming which involves prolonged standing and other rigorous undertakings could be the most probable reason for the increased risk for pre-term birth among such women (Henriksen et al., 1995), thus increased chances of lowbirth weight deliveries. These findings agree with those reported by Kramer (1987).

In studies among pastoralists in Eastern Africa, high proportions of lowbirth weights were associated with the observations that women spend most part of the day standing while looking after cattle or squatting during milking thus straining their bodies and possibly get little time for resting (Kinabo, 1993; Tema, 2006).

Complications during delivery such as placenta abruption and previa have been directly associated with low birth weight. This concurs with the findings from a study done in Colorado, USA which reported that about half of all births complicated by abruption of placenta were low birthweight (Colorado Deptartment of Public Health, 2002).

As expected, low birth weight deliveries were higher in babies whose gestation ages were below 37 full weeks. The findings underlines the effect intrauterine growth restriction rather than prematurity which is a common factor for lowbirth weight in developing countries. This observation is in line with findings by Villar \& Belizan (1982) in a study done in 25 developing settings as compared to findings from developed regions of the world. This could mainly be due to, among other unrecorded factors, poor maternal nutrition and diet around and during pregnancy adversely affect foetal and neonatal outcomes (Kramer et al., 1992; Kind et al., 2006). Similar observations have been reported in Lebanon where pre-term neonates babies comprised of more than $65 \%$ with diabetes being the leading risk factor (Jurjus, 1995).

Low gestation age was the variable that had the highest association with low birth weight. However, preterm and full term babies among the categories of the selected variables could not be compared because the full term neonates who had low birth weights were too few. Low birth weights were significantly associated with low maternal body mass index as a result of low body weight in relation to height. This could be attributed to limited maternal weight gain particularly during the third trimester and other factors that can be associated with decrease in weight including infections. This observation could also be as a result of small statures of some parents in some areas of northern Tanzania who are generally short thus affecting the neonatal phenotype. The association of parental body size with neonatal phenotype was also observed by Leary et al. (2006) in a study where mother-baby relationships were similar in most populations.

Pregnant women who were HIV positive were at increased risk of giving birth to low birth weight babies, most probably due to impaired maternal weight. However the number of HIV infected mothers was too small to warrant a statistical comparison between them and their HIV negative counterparts in terms of factors associated with low birthweight. Moreover levels of HIV infection in this study were not recorded as such these findings could not be exactly comparable to those of Dreyfuss et al. (2001). Being married, housewife and lack of complications during delivery were protective factors for low birth weight outcomes. This could be a result of socio-economic support they get from their husbands such that they were not under such stresses.

It is therefore recommended for an increased promotion of reproductive health in relation to safe motherhood in both females and males at community level so that the latter group could take responsibility for social-psychological, financial and material support to the former. It is important to conduct population based studies in order to obtain more information regarding birth weights such as prevalence and population attributable fraction for feasible interventions. Prevention of HIV infections and better management of malaria and other infections are likely to reduce the incidence of LBW in study area. 


\section{Acknowledgements}

The author wishes to acknowledge Drs. M. Oneko and Longin Barongo for their tireless facilitation of this study. Thanks go to the administration and staff of the Department of Community Health and Medical Records of the Kilimanjaro Christian Medical Centre for permission to access the data. Mr. John Changalucha, Director of Mwanza Medical Research Centre, is thanked for logistical support.

Received 25 July 2005

Revised 18 December 2007

Accepted 19 December 2007

\section{References}

Ahmed, E. \& Behrman, T. ( 1990) Factors and Intervention Associated with Low Birth Weight. Available at http://www.bsetstart.org/resources/lbw aware/lbw rpt/lbw Chap2a. html, accessed on 26/07/2004

Bang, A.T., Bang, R.A., Baitule, SB, Reddy, M.H. \& Deshmukh, M.D. ( 1999) Effect of home based neonatal care and management of sepsis on neonatal mortality: field trial in India. Lancet 354, 1955-1961

Bull, J., Mulvihill, C. \& Quigley, R. (2003) Prevention of low birth weight: A review of reviews for the effectiveness of smoking cessation and nutritional interventions. London: Health Development Agency.

Boerma, J.T., Weinstein, K.I. \& Rutstein, S.O. (1996) Data on birth weight in developing countries: can surveys help? Bulletin of the World Health Organization 74, 209 -216.

Chang, S., O'Brien, K., Nathanson, M.S., Mancini, J. \& Wi, F.R. (2003); African - American teen mothers risk low birth weight. The John Hopkins University Gazette Study 33. Available atttp://www.jhu.edu/ /2003/02sep03/02teens. html. Accessed on $31^{\text {st }}$ December 2003.

Colorado Department of Public Health (2000) Weighing In on Solutions to the Low Birth Weight Problem in Colorado. Available at http://www..cdphe.state.co.us/fc/lbwreport. pdf Accessed on $6^{\text {th }}$ July 2004.

Dreyfuss, M.L., Msamanga, G.I., Spiegelman, D., Hunter, D.J., Urassa, E.J.N., Hertzmark, E. \& Fawzi, W.W. (2001) Determinants of low birth weight among HIV-infected pregnant women in Tanzania. American Journal of Clinical Nutrition 74, 814-826.
Fonseca, W., Kirkwood, B.R., Victoria, C.G., Fuchs, S.R., Flores, J.A. \& Misago, C. (1996) Risk factors for childhood pneumonia among the urban poor in Fortaleza, Brazil: a case-control study. Bulletin of the World Health Organization 74, 199-208.

Henricksen, T. (1995) Factors and intervention associated with low birth weight. Available at http://www.bsetstart.org/resources/lbw aware/lbw rpt/lbw Chap2a.html. Accessed on 26th July 2004.

Henriksen, T. (1999) Foetal nutrition, foetal growth restriction and health latter in life. Acta Pediatrica 429S, 4-8.

Jurjus, A.R. (1995) Low birth wight in Lebanon: morphological parameter and a health status indicator. Eastern Mediterranean Health Journal 1, 194-200.

Kinabo, J. (1993) Seasonal variation of birth weight distribution in Morogoro, Tanzania. East African Medical Journal 70, 752-755.

Klingenberg, C., Olomi, R., Oneko, M., Sam, N. \& Langeland, N. (2003) Neonatal morbidity and mortality in a Tanzanian tertiary care referral hospital. Annals Paediatrics 23, 293-299.

Kramer, M.S., McLean, F.H., Eason, E.L. \& Usher, R.H. (1992) Maternal nutrition and spontaneous pre-term birth. American Journal of Epidemiology 136, 574- 583.

Kramer, M.S. (1987) Determinants of low birth weight: methodological assessment and metaanalysis. Bulletin of World Health Organization 65, 663-737.

Kind, K.L., Moore, V.M. \& Davies, M.J. (2006) Diet around conception and during pregnancy-effects on foetal and neonatal outcomes. Reproductive Biomedical Online 5, 532 -541.

Kusin, J.A., Kardjati, S. \& Renqvist, U.H. (1994) Maternal body mass index: the functional significance during reproduction. European Journal of Clinical Nutrition 48, 56-67.

Leary, S., Fall, C., Osmond, C., Lovel, H., Campbell, D., Erikson, J., Forrester, T., Godfrey, K., Hill, J., Jie, M., Law, C., Newby, R., Robinson, S. \& Yajnik, C. (2006) Geographical variation in relationships between parental body size and offspring phenotype at birth. Acta Obstetric and Gynaecology Scandnavia 85, 1066-1079.

Mathule, M.S.L., Kennedy, T., Gates, G. \& Spicer, M.T. (2005) Predictors of birth weight in healthy women attending a rural antenatal clinic. African Journal of Food, Agriculture, Nutrition and Development 5, 1-18. 
McCormick, M.C. (1985) The contribution of low birth-weight to infant mortality and childhood morbidity. New England Journal of Medicine 312, 82-90.

McLachlan, M. (1999) National Nutrition Project Washington,DC: World Bank

Meis, P.J., Ernest, J.M. \& Moore, M.L. (1987) Causes of low birth-weight births in public and private patients. American Journal of Obstetetrics and Gynecology 156, 1165-1168.

Murphy, C.C., Schei, B., Myhr, T.L. \& Mont, J. (2001) Abuse: a risk factor for low birth weight? A systematic review and meta-analysis. $\mathrm{Ca}$ nadian Medical Association Journal 164, 1567-1572.

Podja, J. \& Kelley, L. (2000) Administrative Committee on Coordination /Sub - Committee on Nutrition. The UN Systems Forum for Nutrition. Nutrition Policy Paper \# 8.

Renqvist, R., Kardjati, S. \& Kusin, J.A. (1994) Martenal body mass index: the functional significancy during reproduction. European Journal of Clinical Nutrition 48, Suppl 3556-3567.

Tema, T. ( 2006) Prevalence and determinants of low birth weight in Jima zone, Southwest
Ethiopia. East African Medical Journal 83, 366-371.

UNAIDS (1999) AIDS epidemic update. Geneva: United Nations Administrative Committee on Coordination Sub Committee on Nutrition (2000). Low Birth Weight. Nutrition Policy Paper No 18.

UNICEF-WHO (2004) United Nations Childrenn's Fund and World Health Organisation, (2004) Low Birth Weight; Country and Global Estimates. UNICEF, New York

Verma, V. \& Das, K.B. (2000) Teenage primigravidae: a comparative study: Available at http://www. hsph.harvard.eu/Organisations/healthnet/Sasia/forums/Nutrition/Nutr/S006. Accessed on

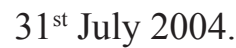

Villar, J. \& Belizan, J. (1982) The relative contribution of prematurity and fetal growth retardation to low birth weight in developing and developed societies. American Journal of Obstetrics and Gynecology 143, 793.

WHO (1980) Division of Family Health and the incidence of low birth weight. A critical review of available information. World Health Statistics Quarterly 33,197-224. 